\title{
sciendo
}

\section{THE REPRODUCTIVE SUCCESS OF FARMED AMERICAN MINK (NEOVISON VISON) - A REVIEW*}

\begin{abstract}
Agnieszka Ludwiczak*, Marek Stanisz
Department of Animal Breeding and Product Quality Assessment, Faculty of Veterinary Medicine and Animal Science, Poznań University of Life Sciences, Złotniki, Słoneczna 1, 62-002 Suchy Las, Poland •Corresponding author: agnieszka.ludwiczak@up.poznan.pl
\end{abstract}

\begin{abstract}
The aim of this review was to define the most important factors that affect the reproductive success of farmed mink. The biology of mink reproduction is unique when comparing it with other farmed fur animals. The article emphasizes the importance of optimal environmental conditions in prevention of reproductive disorders. The novel attempts to the mating schedule, optimal diet and body condition of dams, kits transfer between dams, these are only examples of advantageous procedures used in mink farming to increase the effectiveness of reproduction.
\end{abstract}

Key words: farm-bred mink, reproductive parameters, reproductive success

Although rearing animals for their fur has its opponents claiming that fur is a luxury and unnecessary product, fur farming is one of the most profitable areas of animal production co-operating with other branches of industry, like meat and fish processing plants. The annual economic result of a mink farm is strongly related to the number of pelts sold per year, and their price (Lagerkvist, 1997). The aforementioned relation is not simple, because it is a summation of great variety of effects. The environment of the animals (housing conditions, diet, health) and the genetics (selection), affects both the number of annually produced pelts and their quality. The quality of the pelt directly affects its market value, but the final price depends upon factors that are not related to animal husbandry, like trends in fashion and the dynamics of the international fur market (fluctuations of skin prices, dependent upon the market demand and supply). Most of the pelts produced on-farm are sold through the auction houses, during the annual international fur auctions (Wierzbicki, 2005). The most popular animals raised for fur are mink, foxes and chinchillas. The pelts from farmed American mink (Neovison vison) are currently the most wanted product on

\footnotetext{
*Work funded from statutory activity.
} 
fur auctions, available in a great variety of colour types. The ancestor of the farmed mink is the wild American mink, a predator originating from North America. First farmed mink have been introduced to European farms in the 1920s (Mustonen et al., 2005 a). The studies on wild and farm-bred American mink show a high genetic distance between both groups (Horecka et al., 2012; Thirstrup et al., 2015). The farmed mink is characterized by increased body size, increased craniometrics parameters, diversity of colour types and different structure of coat (shorter and thinner guard hair), when compared to its wild counterpart (Piórkowska and Kowalska, 2014; Taraska et al., 2016). The other obvious results of years of breeding under farming conditions, are significant behavioural changes expressed as decreased fearfulness towards humans, and changes of gastrointestinal functions (Gugołek et al., 2013; Piórkowska and Kowalska, 2014).

Table 1. The literature on mink reproduction

\begin{tabular}{c|c}
\hline Literature & The studied subject/effect \\
\hline 1 & 2 \\
\hline
\end{tabular}

Baekgaard et al., 2008

The effect of female body condition and early kit mortality

Belyaev and Trapezov, 1986

The effect of selection for behaviour on reproduction

Brink and Jeppesen, 2005

Behaviour of mink kits and dams in the lactation period

Dziadosz et al., 2010

The reproduction traits of mink of different colour varieties

Felska-Błaszczyk et al., 2010

The incidence of barren females of various colour types in relation to systems and dates of mating

Hansen and Berg, 2008 a

The effect of selecting for high body weight on litter size and percent kits alive

Houbak and Malmkvist, 2008 Observations of deliveries in mink: potential for more kits

Hunter, 2008

Review of factors associated with mink kit mortality

Johansson and Venge, 1952

Relation of the mating interval to the occurrence of superfetation in the mink

Kemp et al., $1993 \quad$ The effect of different feeding levels during pregnancy on breeding results

Kołodziejczyk and Socha, 2012 Mink fertility of palomino colour type and its crossbreds with standard mink

Lagerkvist et al., 1993, 1994 Selection for litter size, body weight and pelt quality

Malmkvist et al., 2007

Parturient behaviour in relation to early kit mortality

Malmkvist et al., 2016

The effect of litter age and size on maternal motivation

Meagher et al., 2012

Decreased litter size in inactive female mink

Møller, 2008 b

Feeding during gestation in relation to litter size

Murphy, 1979

Schackelford, 1952

Effects of GnRH on plasma LH and fertility in mink

Superfetation in mink

Seremak et al., 2011

The effect of breeding sets arrangement on reproductive parameters in females of the American mink

Seremak et al., 2013

The litter sizes at birth and at 7 days of nursing in mink of different colour varieties 
Table 1 - contd.

\begin{tabular}{l|l}
\hline \multicolumn{1}{c}{1} & \\
\hline Seremak et al., 2016 & Reproductive parameters of female mink of different colour variants \\
Socha and Kołodziejczyk, 2006 & Factors affecting fertility in standard and palomino mink \\
Socha and Markiewicz, 2002 & Effect of mating and whelping dates on the number of kits \\
Sulik et al., 2008 & $\begin{array}{l}\text { Reproduction performance under different mating systems in Sapphire } \\
\text { and Wild mink }\end{array}$ \\
Ślaska et al., 2009 & $\begin{array}{l}\text { Reproductive traits of mink according to their coat colour } \\
\text { Święcicka, 2013 }\end{array}$ \\
Influence of the air temperature and relative air humidity on the param- \\
eters of the reproduction of Scanbrown minks \\
Reproductive results of mink of different colour types \\
Tauson, 1988 & $\begin{array}{l}\text { Effects of level of preceding feed restriction and length of flushing } \\
\text { period on reproductive performance } \\
\text { Tauson, 1993 }\end{array}$ \\
& $\begin{array}{l}\text { Effect of body condition and dietary energy supply on reproductive } \\
\text { processes in female mink }\end{array}$ \\
\hline
\end{tabular}

Currently the American mink is farmed in most European countries, with Denmark and Poland leading with the number of annually produced animals reaching over 17 million and 8.5 million, respectively (data on the European fur sector according to www.fureurope.eu). The annual production cycle typical for mink farms significantly differs from the production of other commercially farmed animals like pigs, cattle or poultry. There are many studies focusing on increasing the reproductive performance of farmed mink and solving problems connected with this topic (Table 1).

The aim of this paper was to analyse the factors that affect the reproductive performance of mink on commercial farms and to present the solutions given in the available literature for the major problems in mink reproduction.

\section{Mink as a seasonal breeder and induced-ovulator}

The American mink has a complex reproductive biology, therefore a successful and economically profitable mink husbandry requires a lot of knowledge and experience (Murphy, 1979). The reproductive success is a result of an annual production cycle ending in November, and covering appropriate management of housing, feeding, health care and of course proper human-animal relationship. Mink farming is based on a strict annual production cycle. Mink is a seasonal breeder with the sexually active period falling in the month of March in the northern hemisphere (Sundqvist et al., 1989). The mating lasts only three weeks resulting in synchronisation of the following production phases: whelping, weaning, growing-up and pelting. Moreover these animals are characterized by an induced ovulation taking place between 36 to 50 hours after mating (Murphy, 1979). A common practice is mating the female on two consecutive days (Johansson and Venge, 1952). The folliculogenesis in mink dams occurs 3-4 times during the breeding season. Over the next 6-10 days (8 days on average) from the mating date, additional ovarian follicles develop and the female 
can be subjected to re-mating (Axelsson et al., 2009). This phenomenon of repeated ovulation is called superfetation and helps to maximize the reproduction success in mink farming by means of different mating schedules (Enders, 1949).

\section{Mating - the optimal date and arrangement of breeding sets}

The effectiveness of mink reproduction depends among others on the optimal organization of the mating system. Before the onset of the mating season the breeders are grouped into breeding sets. Each breeding set is composed from a group of males and usually five groups of females, with males and females within the breeding set being siblings or semi-siblings. A carefully prepared breeding plan leads to the highest reproduction performance of farmed mink. Seremak et al. (2011) analysed the effect of breeding sets arrangement on the reproduction parameters of female mink. The standard design of breeding sets was compared with a modified one (each male was in a close proximity of two females). The mean number of mating encounters per male was higher in the experimental group (modified arrangement) compared to the control, indicating a higher mating activity. The females from the experimental group were characterized by significantly higher average litter size and live births compared to the control group. According to Socha and Markiewicz (2002) the date of mating and whelping significantly affects the reproduction performance of mink. The authors observed that females mated until 5 March and whelped until 25 April were characterized by the highest number of kits born and raised. In their study, Felska-Błaszczyk et al. (2010) analysed the effect of the date of mating and the mating system on the number of barren females of different colour varieties. Three mating systems were used, single mating, double mating (re-mated at 8th day after the first mating) and triple mating (re-mated at 8th and 9th day after the first mating). The use of triple mating allowed decreasing the percent of barren females of all colour varieties. Within the analysed mating dates, the second one (6-10 March) was characterized by the lowest percent of barren females, especially for the Scanblack mink (Table 2). The highest number of fertilized females in the first mating date (1-5 March) was found for the Scanblack mink.

Table 2. Distribution of mated females by mating date (\%) (adapted from Felska-Błaszczyk et al., 2010)

\begin{tabular}{l|c|c|c|c|c}
\hline \multicolumn{1}{c}{ Group of mating } & Scanbrown & Sapphire & Pearl & Scanblack & Total \\
\hline 1 (1-5 March) & 14.92 & 31.89 & 27.4 & 38.16 & 28.74 \\
2(6-10 March) & 65.18 & 44.65 & 51.14 & 48.01 & 51.73 \\
3 (11-15 March) & 8.12 & 15.03 & 9.36 & 6.29 & 9.68 \\
4 (16-20 March) & 10.99 & 7.97 & 11.64 & 7.34 & 9.39 \\
5 (from 21st March) & 0.79 & 0.46 & 0.46 & 0.21 & 0.46 \\
\hline
\end{tabular}

\section{Gestation and whelping}

The most serious problem considering gestation is the variety in its length affected by delayed embryo implantation, called diapause. The implantation takes place at the beginning of April, regardless of the mating date (Murphy and James, 1974; 
Concannon et al., 1980; Cao et al., 2016). Therefore the gestation length is affected by the mating date, and defined as the number of days from the last mating until whelping. The gestation may last from 35 to 86 days, with the dark-fur mink showing greater variety in gestation length than light-fur mink (like Sapphires) (Sulik et al., 2008). According to the research of Święcicka (2013), the length of gestation in the Scanbrown mink is affected by the air temperature and relative air humidity. The author also reported that the optimal gestation length (45-60 days for the Scanbrown dams) allows obtaining larger litters, through reduction of kit mortality. In case of gestations shorter than 40 days or longer than 65 days, a large number of dead kits was observed. Moreover Święcicka (2013) reported the largest number of litters at the end of April, and the first days of May (air temperature $16^{\circ} \mathrm{C}$; air humidity $60-65 \%$ ) when about $40 \%$ of females whelped (Table 2). According to Seremak et al. (2016) the gestation length is also dependent upon the genotype and varies within different mink colour types from 53.8 to 56.6 days.

\section{Litter size - the number of stillborns, mortality in the first days of life, the number of raised kits}

The large litter size at birth does not always mean high number of kits at weaning. The newest methods used for observation of mink dams during deliveries (based on video recordings), revealed that the litter size at birth (including stillborns) averages even up to $9.5 \mathrm{kits}$, showing that mink dams have a potential to produce big litters (Houbak and Malmkvist, 2008). There is a number of factors related to increased kit mortality: birth of stillborn or weak kits, too low birth weight, too low maternal skills of the dam, low milk production or the development of mastitis, pre-weaning diarrhea known as 'sticky kits' syndrome (Hunter, 2008). All the aforementioned composites of mink kits mortality have their own background. According to the current state of knowledge, the highest mortality ranging from $60 \%$ to $70 \%$ total deaths, is recorded among kits during first seven days postpartum. The average level of kit mortality from birth until weaning (between 7 and 8 weeks of age) reaches from $10 \%$ up to $30 \%$. One of the factors directly linked to early kit mortality is prolonged parturition, associated with lower viability of kits due to hypoxia and reduction of the female nursing behaviour (Malmkvist et al., 2007). The optimal duration of parturition in mink averages from 5 to 6 hours. According to the literature, deliveries that average 10 hours or more result in increased kit mortality and decreased nursing behaviour. The increased duration of deliveries in mink is associated to their improper body condition and no access to nest building materials (Houbak and Malmkvist, 2008). According to Maciejowski and Jeżewska (1993) the smaller size of the first litter compared to the following litters is often observed in mink, as well as the fact that the reproductive performance of females increases to a certain age, and then it gets lower. The early mortality of kits may be limited by a simple management procedure like fostering kits from large litters to dams with small litters, or fostering kits in case the female is not taking proper care of her offspring (Fink et al., 2004). In their study, Socha and Kołodziejczyk (2006) analysed the effect of colour type, age and mating date on the reproduction results in Standard and Palomino mink. They reported that the Standard mink show the largest litter size at weaning in the 
second year of reproduction, while the Palomino females produced the largest litters in the second and third year of reproduction. The authors also found that the number of weaned kits was affected by the date of whelping, and the females that gave birth before the 25th of April were characterized by larger litters at weaning (a mean of 5.4 kits) compared to the dams that whelped at a later time. The females that gave birth after 5th May were characterized by the smallest number of weaned kits (3.7 for the Standard, and 4.5 for the Palomino colour type). The level of milk production in lactating females is also mentioned among factors crucial for the weaning success and kit survival in mink. One of important factors associated with the level of lactation in mink dams is the development of mammary glands (Møller, 2008 a). There is also a group of diseases that may increase the mortality of kits in the suckling period. One of the most mentioned diseases is the 'sticky kits' syndrome, a preweaning diarrhea observed in 4- to 6-week-old kits (Birch et al., 2017). The 'sticky kits' syndrome is a multifactorial disease. Its outbreaks on mink farms are associated with farm size, energy supply per female in the gestation period, and animals that enter the farm in an uncontrolled manner (dogs, cats, wild mink and foxes). The number of live kits at weaning is clearly dependent upon the maternal care in mink. Mink dams are good mothers, spending a lot of time on infant care. The kits in the first 4-6 weeks of their lives are fully dependent on the dam, as she provides them milk and heat (Brink and Jeppesen, 2005; Malmkvist et al., 2016). Brink and Jeppesen (2005) analysed the behaviour of kits between 21 and 56 days of age. The authors observed that about $20 \%$ of litters began to drink water 38 days after birth, while eating solid feed was observed from 21-26 days. The number of kits showing both these behaviours increased from 21 to 56 day of age. The weaning age of kits is crucial for their survival. Prior to separation, the kits should be nutritionally independent from their mother (Martin, 1984). According to the literature the optimal time of weaning is when the kits are between 6 and 8 weeks of age. Optimal means good for both the dam and her offspring. The 6- to 8-week-old kits rely on solid food, drink water from the nipple-drinker, and self-regulate their body temperature. Of course it would be beneficial for the kits to stay longer with their mother, but too long suckling period is not good for the dam. There is a series of reasons that supports this statement, including the fact that the mother cannot get away from her kits like mink dams do in the wild, and that large litters negatively affect the condition of the dam. The cortisol levels in mink dams kept too long with their litters clearly indicate stress (Malmkvist et al., 2007). Moreover earlier weaning has shown to reduce the cases of the nursing sickness among mink dams (Schneider and Hunter, 1993).

\section{The housing conditions - cage type and equipment, exposition to the natural photoperiod}

The housing conditions of mink include the use of individual or social cages, exposure to the natural photoperiod and the use of cage enrichments. Proper housing decides about the welfare of animals, and obviously poor welfare is associated with low production results (Henriksen et al., 2015; Schneider and Hunter, 1992). The housing system on mink farms is defined by the cage size, design and the group size. Exact housing conditions for farmed mink are defined by law regulations, and must 
meet the requirements of these animals (Díez-León et al., 2017). The adult mink are single housed in standard cages from wire net. Each animal has access to a wooden nest box with a wire floor. In the winter season the nest boxes are embedded with a thick layer of straw, and additionally the nest box wire lid is covered with straw to ensure protection from low temperatures (Axelsson et al., 2009; Damgaard et al., 2012). One of the most interesting aspects of housing mink is the role of straw in the annual production cycle. Access to straw is obviously very important in the pre-whelping period for building nests in delivering dams. But its role is not limited to maternal nest-building. Mink may eat the straw (especially during the slimming period), play with it (straw plays a role of a cage enrichment) or build nests outside the whelping period (Malmkvist and Schou, 2017). In mink farming exposure of the animals to the natural photoperiod is crucial for the proper cycle of hair replacement (Blomstedt, 1989). The most important moment is the autumn moulting, as it leads to the development of the winter coat being of the highest economical value for the fur industry. Exposition of farmed mink to natural photoperiod decides not only about the proper fur development but also about the proper course of the reproduction cycle, as the increasing day length triggers the oestrus in mink females (Sundqvist et al., 1989). Because of the role of day length in the mink physiology, the animals are kept under sheds allowing for exposure of these animals to changing day length, but at the same time protecting them from direct influence of bad weather conditions like rain, wind or snow. According to literature the improper management of mink on farms leads to the health and reproduction disorders. Rouvinen-Watt and Hynes (2004) analysed in their study the relation of ranch-level factors to occurrence of the nursing sickness. The factors analysed included: the distance between sheds, the shed orientation (North-South, East-West), the shed type (two-row or multi-row), the roofing material and the type of watering system (water cups, automatic nipple). The authors reported that there were differences in the aforementioned factors between the farms, showing high incidence of this metabolic disorder and those farms with rare occurrence of mink nursing sickness.

\section{Diet, feeding management and feed quality}

Proper nutrition is one of the major factors affecting the reproduction results in farm-bred mink. The annual production cycle on mink farms has been divided into four periods, according to the physiological state of animals and their nutritional needs. The diet of breeders is characterized by higher share of metabolizable energy (ME) from protein and lower share of ME from fat, compared to the diet of growingfurring juveniles. In the pre-mating and mating season the breeders are fed according to their body weight. Mink dams in lactation have very high energy demands, and weight losses are common among females in this period (Fink et al., 2004). According to the some research, the restricted energy supply in diets for pregnant and lactating females has an advantageous impact on the whelping success (Bis-Wencel, 2006). Bis-Wencel (2006) in her study analysed the effect of energy level in mink diets on reproduction parameters of females. The females fed with low energy diets (1080 kcal ME/kg; 48.8\% ME from protein, 37.8\% ME from fat, 13.4\% ME from carbohydrates) showed much better reproduction results compared to females fed 
higher energy diet (1260 kcal ME/kg; 46.2\% ME from protein, 41.3\% ME from fat, $12.5 \% \mathrm{ME}$ from carbohydrates). As a result of their studies, Fink et al. (2004) suggest increasing the share of ME from carbohydrates to receive the optimal body condition and daily feed intake of lactating females. In their study, they analysed the effect of different protein:carbohydrates ratio, ranging from 63:5 in low carbohydrate diet (LC), 48:15 in the medium carbohydrate diet (MC), to 34:33 in the high carbohydrate diet (HC). The results indicated that LC diet increases the daily feed intake compared to $\mathrm{HC}$ diet (306 g vs $244 \mathrm{~g}$ ), and caused a higher weight loss from the first to the fourth week postpartum (10\% in LC vs $3 \%$ in $\mathrm{MC}$ vs $1 \% \mathrm{HC})$. Obviously, animals supplied with feed that does not meet their nutrient requirements, will respond with the increase of feed intake. Moreover the diet of dams affected their daily milk yield. Jiang et al. (2015) have studied the effect of dietary protein on the reproduction parameters of mink dams. According to their results, about $36 \%$ of $\mathrm{ME}$ from dietary protein results in optimal reproductive performance. Both too high and too low level of protein, adversely affects the birth rate in female mink. In the study of Matthiesen et al. (2010), they have fed the experimental group of pregnant mink with low-protein diet (14\% of ME from protein), and found and effect of low foetal life protein provision in following generations, at the molecular level. Jiang et al. (2018), in their experiment, proved that diets characterized by similar nutritional value, may significantly differ in the protein and fat digestibility. On the basis of their results, the authors pointed out that lower digestibility of nutrients may impair the reproductive performance of female mink, causing higher percentage of barren females and reduced birth weight, compared to the group fed a diet with optimal digestibility.

Feed quality is a very important environmental factor in the husbandry of farmed animals. Farmed mink are fed with wet feed based mainly on animal by-products, but also including plant-origin ingredients and essential supplements (vitamins, minerals). The by-products from processing poultry and aquatic animals like fish or clams, are the major component of mink feed (Campbell et al., 2016; Damgaard et al., 2004, 2012). The fact is that farmed mink (and other carnivorous fur-bearers) naturally utilize huge amounts of animal by-products not suitable for human consumption (Ahlstrøm et al., 2008; Pölönen et al., 2004). The properly prepared mink feed is distributed by man-driven machines and applied on the top of the wire cage or on the top of the nest box wire lid, depending on the season (Malmkvist et al., 2016). Unfortunately animal by-products are prone to biological contamination. The fact that mink feed is a concentrated source of proteins, is high in moisture and finely comminuted, makes it a perfect environment for the development of pathogenic bacteria. Especially dangerous for the quality and safety of mink feed is the increased temperature in the summer months (Jensen et al., 2016, 2017). Improper management of this type of feed fosters not only the development of bacteria, but also protein and fat oxidation leading to decreased nutritional value of the feed and to the production of potentially toxic compounds (Papuc et al., 2017). The wet feed used in mink production may be also contaminated with mycotoxins (the source are the plant-based ingredients) or chemically contaminated (too high concentration of feed preservatives, residues of disinfection agents). Therefore, in order to promote the health of farmed 
mink, it is crucial to monitor the quality of feed and care about proper transport, storage and processing of mink feed (Christiansen and Lassén, 2008).

The seasonal changes of body weight observed in mink are part of their biology, and depend upon the natural photoperiod and the level of endocrine hormones. While the excessive body weight characterising farmed mink around the autumn-winter period is to a high extent associated with a high energy diet offered to these animals so they can reach high body weight at pelting. Unfortunately there is a physiological relationship between the body condition and the reproductive performance of animals. Research indicates that obesity in female mink is connected with increased levels of adipokines, like leptin, and results in reproductive impairment (Mustonen et al., 2005 b). Because of a negative relation between high body weight and reproduction results (over-conditioned females have problems with parturition, while males do not show willingness to mate) the typical practice preceding mating on mink farms, is slimming the animals (Baekgaard et al., 2008; Fink and Tauson, 1998; Korhonen and Niemelä, 1998; Tauson, 1993; Tauson et al., 2000). The other equally important aspect of slimming is the induction of flushing in female mink. The results of research on the reproductive performance of mink show a positive effect of slimming followed by ad libitum feeding on the litter size (Kemp et al., 1993; Tauson, 1988; Møller, 2008 b). On the other hand inadequate energy supply during the breeding season and pregnancy has been recognized as a risk factor for metabolic diseases among mink like the 'nursing sickness' (Rouvinen-Watt and Hynes, 2004; Schneider and Hunter, 1993; Schneider et al., 1992). The number of barren females also decides about the economic success of a mink farm. According to the available knowledge, proper feeding plays also an important role in proper course of gestation in mink dams (Clausen and Hammer, 2008). Boudreau et al. (2014) analysed the effect of the feeding strategy on the reproductive success of mink. The authors reported that the standard feeding strategy including ad libitum feeding of mink in the summer months to reach the highest body weight at pelting is not good either for the health of the animals or for the commercial success of the mink farm. The authors reported that the caloric restriction instead of ad libitum feeding allows breeders to maintain a proper body condition in the fall, therefore there is no need for slimming the animals prior to the mating season. Moreover, restricted females showed better reproductive results compared to ad libitum fed ones, that is a larger number of live kits at birth ( 5.88 vs 4.62 kits, $\mathrm{P}<0.05)$. The restrictively fed animals were characterized by no fluctuations of body weight or condition during the annual production cycle.

\section{Animal selection (litter size, body weight) and colour type}

The aim of artificial selection of farmed mink is to increase the genetic merit of animals and improve economically important traits - body size, litter size and fur quality. Another important aspect of mink selection is reduction of inbreeding and selection against stereotypical behaviour or selection of disease-resistant animals (Svendsen et al., 2007). Selection takes places before pelting. Live animals are graded considering the body size and fur quality (colour darkness, colour clarity, guard hair coverage and underfur density) (Koivula et al., 2008). In case of females, 
the reproductive performance is also taken into account (litter size). The results of this selection help to decide if the animal should be left for breeding or pelted. The final information about the pelt quality (pelt size, colour type, colour clarity, fur quality) is based on the results of grading dried pelts in auction houses and decides about the price of the pelt (Kołodziejczyk and Socha, 2008). The available literature indicates that properly conducted selection allows gradually improving all the economically important traits. The heritability of litter size in mink ranges from 0.12 to 0.20 , while the heritability of the body size ranges from zero to 0.51 (Koivula et al., 2008). Unfortunately selection for the litter size does not go hand in hand with selection for the body weight, as these two traits are negatively correlated (Lagerkvist et al., 1993, 1994; Rozempolska-Rucińska, 2004). A negative correlation has been also found between the litter size and fur quality. Lagerkvist et al. (1994) selected farmed mink for a group of functional traits, including improved litter size. The authors reported negative maternal effects on the aforementioned reproductive trait and reaffirmed that heavy animals (both males and females) were unwilling to mate. Hansen and Berg (2008 a) reported that mink selection for high body weight may result in decreased litter size and increased kits mortality, clearly indicating a negative correlation between these traits. However according to Hansen and Berg (2008 b) the genetic potential defining the body weight of mink kits is associated not only with their own capacity for growth but also with the capacity of the female to promote kits' growth. Moreover, Hansen et al. (2008) reported that the effect of crossbreeding (heterosis) may be used to improve litter size and kit survival. Many authors studying the reproductive parameters of farmed mink conclude about differences between colour types (Dziadosz et al., 2010; Socha et al., 2003; Socha and Kołodziejczyk, 2006; Sulik et al., 2008; Ślaska et al., 2009; Seremak et al., 2013) Seremak et al. (2013) analysed the distribution of litter sizes depending on the colour type of mink (Table 3). According to these authors the most frequent litter size in the Black Velvet was 8 and 7 kits (20.77 and 20.00\%), in White Hedlund - 4 kits $(17.69 \%)$ and in the Silverblue -9 and 10 kits (23.85 and 20.00\%) (Table 3). The highest mortality among kits in the first seven days after birth was recorded for the Hedlund White and averaged $38.7 \%$. The level of kit mortality was also affected by the litter size, and was the highest for large litters (10-11 kits) as well as single births. Kołodziejczyk and Socha (2012) also concluded about the effect of genetic group on the reproductive performance of female mink. The authors found that crossbreeding between colour types positively affects the fertility, litter size at birth and at weaning. The research results presented by Święcicka et al. (2016) support the statement about the effect of colour type on the reproductive performance of mink. The Pastel and Cross females were characterized by the highest fertility, number of kits at birth and percent of weaned kits. The Standard type had the lowest number of kits at birth, while the Sapphires had the lowest percent of weaned kits. Other authors (Socha et al., 2003; Dziadosz et al., 2010) also confirm the poor reproductive performance of Sapphire females. According to Dziadosz et al. (2010) Scanblack females are characterized by better reproductive performance compared to Scanblack Velvet, Hedlund White, Regal White and Sapphire Cross females. The number of weaned puppies was lower for Regal White females compared to other analysed colour types. 
Table 3. Percent of litters of different size at birth in some colour types of mink (\%) (adapted from Seremak et al., 2013)

\begin{tabular}{l|c|c|c|c}
\hline \multirow{2}{*}{ Litter size } & \multicolumn{4}{|c}{ Colour type (\%) } \\
\cline { 2 - 5 } & Black Velvet & Hedlund White & Silverblue & Total \\
\hline 1 & 3.08 & 10.00 & 6.92 & 6.67 \\
2 & 4.62 & 8.46 & 3.85 & 5.64 \\
3 & 5.38 & 6.92 & 2.31 & 4.87 \\
4 & 5.38 & 17.69 & 0.77 & 7.95 \\
5 & 3.85 & 10.77 & 2.31 & 5.64 \\
6 & 18.46 & 11.54 & 7.69 & 12.56 \\
7 & 20.00 & 10.77 & 8.46 & 13.08 \\
8 & 20.77 & 6.92 & 19.23 & 15.64 \\
9 & 13.85 & 8.46 & 23.85 & 15.39 \\
10 & 3.08 & 6.15 & 20.00 & 9.74 \\
11 & 1.54 & 2.31 & 4.61 & 2.82 \\
Mean litter size, & 6.58 & 5.35 & 7.61 & 6.51 \\
number of pups & & & & \\
\hline
\end{tabular}

\section{Behaviour}

Research results in the field of behaviour in commercial mink indicate that the temperament of farmed mink and the level of stereotypies affects both the effectiveness of reproduction and the quality of skins at the pelting time (Hansen and Jepesen, 2006). According to the available literature, the goal of animal breeding should be the adaptation of farmed animals to intensive farming conditions, not the reverse (Malmkvist and Hansen, 2001). Commercial mink show domestic behaviour. Excessive fear towards humans, aggression, infanticide or stereotypies (fur biting) are unwanted among farmed animals, therefore the animals that express such abnormal behaviours are removed from the farm. Domesticated behaviour is clearly visible especially among bright colour types of mink, like the Sapphire. Domestication is connected with mutation in genes responsible for the metabolism of brain serotonin playing a role of aggression inhibitor (Trapezov, 2008). In order to limit the incidence of abnormal behaviour mink are offered cage enrichments (for example shelf, plastic cylinder, plastic bandy ball).

The wild American mink (Mustela vison) is an active hunter showing aggression towards its conspecifics as part of a territorial behaviour. The same rule applies to the farmed animals of this species, therefore the adult mink are kept in single pens. Opposite to adults, juvenile mink are kept in groups to meet their need to express social behaviours. Social behaviours develop very early in life. Brink and Jeppesen (2005) reported first recordings of play behaviour among mink kits aged from 27 to 32 days. Therefore group housing of juvenile mink is an important aspect of their welfare. Depending on the number of animals placed per cage, and the share of males and females in one group, different level of social tolerance can be observed. If the tolerance is low, increased aggression may occur, causing both the decrease of the animal 
welfare and skin damages. A very good indicator of the level of aggression among mink are so called 'bite marks', dark spots observed on the leather side of the skin (Pedersen et al., 2004). Hansen et al. (2014) analysed the occurrence of bite marks and fur chewing in group housed mink. They reported that the number of bite marks is a good indicator of social tolerance only for dark coloured mink and changes with the age of mink separation from group housing to individual housing (20-26 weeks of age; $\mathrm{P}<0.001$ ). Moreover the authors found a variety in the number of bite marks for analysed body regions (neck, body and tail) depending on the separation age. On the basis of their observations Hansen et al. (2014) suggested that the marks on the body and tail are caused by aggression between cage-mates, while the marks on the neck are associated with sexual behaviour. The marks indicating fur chewing decreased with separation age of group housed mink (from 16 to 28 weeks of age; $\mathrm{P}<0.001)$. Hänninen et al. (2008) compared two housing systems: male-female pairs in standard cages and family housed mink (connected standard cages in order to house 5-9 siblings and their mother). On the basis of the number of scars on the skin and fur defects, the authors concluded that aggressive behaviour occurs less in pair-housed mink. Axelsson et al. (2017) analysed the effect of the cage design (standard vs climbing cages) and group size (pairs vs four juveniles per cage) on the occurrence of stereotypic behaviours in mink. The number of bite marks on the leather side of the skins was used as the indicator of the level of aggression among pen-mates. The authors found that larger animal groups had a negative influence on the growth and skin length of male mink $(\mathrm{P}<0.001)$. While the cage design had no significant effect on the occurrence of bite marks on mink skins.

One of the on-farm procedures that might negatively affect the animal welfare is the process of slimming preceding the mating season in the month of March. Slimming is based on restrictive feeding of obese females. One of the negative consequences of slimming is the increase of stereotypies or excessively decreased body weight (Tauson, 1993; Mason and Mendl, 1997). The answer to the aforementioned problems is the individual treatment of animals including the nutrient level corresponding to their condition scores and careful observation of animals. Damgaard et al. (2004) analysed the behaviour of female mink in the winter period as related to the feeding strategy (ad libitum vs restrictive feeding in the period from 16 October to 16 February). They observed that over $50 \%$ of restrictively fed females expressed stereotypic behaviour compared to $27 \%$ of the ad libitum fed animals $(\mathrm{P}<0.05)$. Moreover the stereotypical behaviour occurred before feeding time, not after. According to Damgaard et al. (2012) the restrictively fed female mink are more active compared to ad libitum fed ones $(\mathrm{P}=0.020)$.

There are also research papers discussing the relation between behaviour of farmed mink and their reproductive performance (Belyaev and Trapezov, 1986; Korhonen et al., 2002). Abnormal behaviour negatively related to the reproduction results of farmed mink covers stereotypies and infanticide. However not all authors report infanticide, but rather an adaptive behaviour consisting of feeding already dead kits (Malmkvist et al., 2007). The human factor cannot be ignored in the analysis of commercial mink behaviour. Proper quality of handling farm-bred mink by the stock people, positively affects the breeding parameters (Seremak et al., 2011). 


\section{Conclusions}

The presented review underlines the unique and complex biology of American mink. The reproductive physiology of mink, in its current shape, perfectly 'fits in' the on-farm annual production cycle. However there are still some aspects that need to be improved. Although farmed mink are able to deliver numerous litters, the high mortality during their first days of life is still a common problem. The reproductive success seems to be an output of all the analysed factors, including optimal housing, feeding, body condition, proper level of maternal instinct, and genetic selection.

\section{References}

Ahlstrøm Ø., Skrede A., Shearer K. (2008). Perspectives on traditional and alternative feed ingredients in future fur animal production. Scientifur, 32: 116-122.

A x e ls s on H.M.K., A ldén E., Li d fors L. (2009). Behaviour in female mink housed in enriched standard cages during winter. Appl. Anim. Behav. Sci., 121: 222-229.

A xelss on H.M.K., Hansen S.W., Loberg J., Lidfors L. (2017). Effects of group size on behaviour, growth and occurrence of bite marks in farmed mink. Appl. Anim. Behav. Sci., 194: $112-119$.

B a e k g a ard H., L a r s e n P.F., S $ø$ n d e r u p M. (2008). Female body condition and early kit mortality: A description from practice. Scientifur, 32: 18-19.

B e ly a e v D.K., Trape z ov O.V. (1986). The relationship of selection for behaviour with reproduction in American mink. Zh. Obshch. Biol., 47: 445-450.

B i r c h J.M., A g g e r J.F., D a hl in C., J e n s e n V.F., H a m m e r A.S., S tru ve T., J e n s e n H.E. (2017). Risk factors associated with diarrhea in Danish commercial mink (Neovison vison) during the pre-weaning period. Scientifur, 41: 76-78.

B i s - We n c e 1 H. (2006). The diet effect on the indices of female minks reproduction (in Polish). Acta Sci. Pol., Medicina Veterinaria, 5: 103-110.

B 1 o mstedt L. (1989). Histological determination of different stages of pelage development, fur growth of mink. Acta Agric. Scand., 39: 91-99.

B oudreau L., B enkel B., A statkie T., Rouvinen-Watt K. (2014). Ideal body condition improves reproductive performance and influences genetic health in female mink. Anim. Reprod. Sci, 145: 86-98.

B r in k A.L., J e p p e s e n L.L. (2005). Behaviour of mink kits and dams (Mustela vison) in the lactation period. CJAS, 85: 7-12.

Campbell D.L.M., Link J.E., Lester-Saenz A.H., Bursian S.J. (2016). Feed intake, growth, and behavioral assessment of mink fed a clam-based diet. CJAS, 96: 11-18.

Ca o X., We i H., Xue H., Li X., Zha o W., Xu C., Wang S., D i a o Y., Ros e J., Xu B. (2016). Fecal progestin concentrations as an indicator of reproductive success in American mink. Anim. Reprod. Sci., 165: 11-16.

Chr r s t i a n s en M.L.E., L a s s én T.M. (2008). Processing of animal by-products used in feed for fur animals - effect on nutritional value and hygienic quality. Scientifur, 32: 123-127.

$\mathrm{C} 1$ a u s e n T.N., H a m m e r A.S. (2008). Placental scars in barren mink females. Scientifur, 32: 32-33,

Con c a n n on P., P i 1 be a m T., Travis H. (1980). Advanced implantation in mink (Mustela vison) treated with medroxyprogesterone acetate during early embryonic diapause. J. Reprod. Fertil., 58: $1-6$.

D a mg a ard B.M., Han sen S.W., Børsting C.F., Mø11 er S.H. (2004). Effects of different feeding strategies during the winter period on behaviour and performance in mink females (Mustela vison). App. Anim. Behav. Sci., 89: 163-180.

D a $\mathrm{m} g$ a a r d B.M., D $\mathrm{l} g$ a a r d T.S., L a r s e $\mathrm{n}$ T., H e d e m a n n M.S., H a n se n S.W. (2012). The effects of feed restriction on physical activity, body weight, physiology, haematology and immunology in female mink. Res. Vet. Sci., 93: 936-942. 
Díez-Léón M., Qu in ton M., M a s on G. (2017). How tall should a mink cage be? Using animals' preferences for different ceiling heights to improve cage design. App. Anim. Behav. Sci., 192: 24-34.

D zi a dosz M., S e remak B., La s o ta B., Masłowska A., M i eleń c zuk G. (2010). Analysis in some reproduction traits of female mink (Neovison vison) depending on the colour varieties and age. Acta Sci. Pol., Zootech., 9: 71-80.

En de r s R.K. (1949). Multiple ovulation in mink breeding. Am. Fur Breeder, 21: 6-8.

Felska-Błaszczyk L., Sulik M., Panknin A. (2010). The incidence of barren females of mink (Mustela vison) of various colour types in relation to systems and dates of mating (in Polish). Acta Sci. Pol., Zootech., 9: 81-92.

F in k R., Ta u s o n A.H. (1998). Flushing of mink (Mustela vison): effects on energy metabolism and some blood metabolites. Anim. Sci., 66: 277-284.

F in k R., Tau s on A.H., Chw a libog A., Kristens en N.B., Wa mberg S. (2004). Effects of substitution of dietary protein with carbohydrate on the lactation performance in the female mink (Mustela vison). J. Anim. Feed Sci., 13: 647-664.

Gugołek A., Zalewski D., Strychalski J., Konstantynowicz M. (2013). Food transit time, nutrient digestibility and nitrogen retention in farmed and feral American mink (Neovison vison) - a comparative analysis. J. Anim. Physiol. Anim. Nutr., 97: 1030-1035.

Hänninen S., Mononen J., Harjunpää S., Pyykönen T., Sepponen J., Ahola L. (2008). Effects of family housing on some behavioural and physiological parameters of juvenile farmed mink (Mustela vison). App. Anim. Behav. Sci., 109: 384-395.

Hansen S.W., Jep pes en L.L. (2006). Temperament, stereotypies and anticipatory behaviour as measures of welfare in mink. App. Anim. Behav. Sci., 99: 172-182.

H a n s e n B.K., B erg P. (2008 a). Reduced litter size and percent kits alive is a consequence of selecting for high body weight. Scientifur, 32: 16.

H a n s e n B.K., B erg P. (2008 b). Genetics of early kit growth and maternal weight changes during pregnancy and lactation in mink. Scientifur. 32: 24-25.

H a n s e n B.K., B e rg P., L a r s e n P.F. (2008). Heterosis in mink. Scientifur, 32: 77b-77c.

Hansen S.W., Møller S.H., D a m ga ard B.M. (2014). Bite marks in mink - induced experimentally and as reflection of aggressive encounters between mink. App. Anim. Behav. Sci., 158: 76-85.

He n ri k s e n B.I.F., A n n e b e rg I., Søren s e n J.T., Mølle r S.H. (2015). Farmers' perception of stable schools as a tool to improve management for the benefit of mink welfare. Livest. Sci., 181: $7-16$.

Horecka B., Jeżewska - Witkowska G., Kasperek K., Jakubczak A., Ślaska B., B u g n o-P on i ew i ers k a M., P i órk ow s k a M. (2012). Genetic structure of wild and farmbred American mink (Neovison vison). Proc. XXV International Conference Genetic Days. Book of Abstracts. 18-20.09.2012, Wrocław, Poland, p. 65.

Houbak B., Malmkvist J. (2008). Observations of deliveries in mink: Potential for more kits. Scientifur, 32: 34-35.

H u n t e r D.B. (2008). Review of factors associated with mink kit mortality. Scientifur, 32: 28-29.

J en sen V.F., S o m mer H.M., Struve T., Claus en J., Chriél M. (2016). Factors associated with usage of antimicrobials in commercial mink (Neovison vison) production in Denmark. Prev. Vet. Med., 126: 170-182.

J en se n V.F., S om mer H.M., Struve T., Claus en J., Chriél M. (2017). A cross-sectional field study on potential associations between feed quality measures and usage of antimicrobials in commercial mink (Neovison vison). Prev. Vet. Med., 143: 54-60.

Ji ang Q., Li G., Zh ang T., Zhang K., G a o X., Xing Y., Zh a o J., Yang F. (2015). Effects of dietary protein level on nutrients digestibility and reproductive performance of female mink (Neovison vison) during gestation. Anim. Nutr., 1: 65-69.

Jiang Q., Li G., Zhang T., Zhang K., Gao X., Xing Y., Yang F. (2018). Application of formulated diets and their effects on nutrient digestibility and reproductive performance of females mink (Neovison vison) during gestation. J. Appl. Anim. Res., 46: 125-129.

J o han s s on I., Ven ge O. (1952). Relation of the mating interval to the occurrence of superfetation in the mink. Acta Zool., 32: 255-258. 
K e m p B., M a r t e n s R.P.C.H., H a z e 1 e g e r W., S o e d e N.M., N o o r d h u is e n J.P.T.M. (1993). The effect of different feeding levels during pregnancy on subsequent breeding results in mink (Mustela vison). J. Anim. Physiol. Anim. Nutr., 69: 115-119.

Koivula M., Strandén I., Mäntys a ri E.A. (2008). Genetic parameters for litter size and grading traits in Finnish mink population. Scientifur, 32: 51-58.

K ołodziejczyk D., S ocha S. (2008). Analysis of conformation traits in mink of standard and palomino colour types. Scientifur, 32: 59-62.

K ołodzi ej c z y k D., S o cha S. (2012). Mink fertility of palomino colour type and its crossbreeds with different percentages of standard mink genes. Acta Sci. Pol., Zootech., 11: 53-60.

K o r h o n e n H., N i e m e lä P. (1998). Effect of ad libitum and restrictive feeding on seasonal weight changes in captive minks (Mustela vison). J. Anim. Physiol. Anim. Nutr., 79: 269-280.

Korhonen H.T., Jauhia inen L., Rekilä T. (2002). Effect of temperament and behavioural reactions to the presence of a human during the pre-mating period on reproductive performance in farmed mink (Mustela vison). CJAS, 82: 275-282.

L a ger kvis t G., J o han s s on K., Lund e he i m N. (1993). Selection for litter size, body weight and pelt quality in mink (Mustela vison): experimental design and direct response of each trait. J. Anim. Sci., 71: 3261-3271.

La ger kvis t G., J o han s s on K., L un d e h e i m N. (1994). Selection for litter size, body weight, and pelt quality in mink (Mustela vison): correlated responses. J. Anim. Sci., 72: 1126-1137.

L a ger k vis t G. (1997). Economic profit from increased litter size, body weight and pelt quality in mink (Mustela vison). Acta Agr. Scand. A-An., 47: 57-63.

Mac i j ows ki J., J ėzews ka G. (1993). Genetics of reproduction traits of fur animals (in Polish). Zesz. Nauk. Prz. Hod., 12: 5-12.

Malmkvist J., Hansen S.W. (2001). The welfare of farmed mink (Mustela vison) in relation to behavioural selection: a review. Anim. Welf., 10: 41-52.

Malm k vis t J., G a d e M., D a m m B.I. (2007). Parturient behaviour in farmed mink (Mustela vison) in relation to early kit mortality. Appl. Anim. Behav. Sci., 107: 120-132.

Malm kvist J., Sørensen D.D., Larsen T., P a l m e R., H a n sen S.W. (2016). Weaning and separation stress: maternal motivation decreases with litter age and litter size in farmed mink. Appl. Anim. Behav. Sci., 181: 152-159.

M a l m k v is t J., S c h o u T.M. (2017). Year-round use of straw in farm mink. Scientifur, 41: 92.

M a rtin P. (1984). The meaning of weaning. Anim. Behav., 32: 1257-1258.

M a s o n G., M e n d 1 M. (1997). Do the stereotypies of pigs, chickens and mink reflect adaptive species differences in the control of foraging? Appl. Anim. Behav. Sci., 53: 45-58.

Mat th i e s e n C.F., B 1 a ch e D., Th o m s en P.D., Ta u s on A.H. (2010). Feeding mink (Neovison vison) a protein restricted diet during pregnancy induces higher birth weight and altered hepatic gene expression in the F2 offspring. Br. J. Nutr., 104: 544-553.

Mø 11 e r S.H. (2008 a). Development of mammary glands in mink. Scientifur, 32: 22-23.

Mø 11 e r S.H. (2008 b). Feeding during gestation in relation to litter size in mink. Scientifur, 32: $20-21$.

M u r p h y B.D. (1979). Effects of GnRH on plasma LH and fertility in mink. CJAS, 59: 25-33.

Murphy B.D., J a m e s D.A. (1974). The effects of light and sympathetic innervation to the head on nidation in mink. J. Exp. Zool., 187: 267-276.

Mustonen A.M., P y y kön en T., P a a k k on en T., Ry ök k ynen A., A s i ka in en J., A ho J., Mononen J., Ni e minen P. (2005 a). Adaptations to fasting in the American mink (Mustela vison): Carbohydrate and lipid metabolism. Comp. Biochem. Physiol. A Mol. Integr. Physiol., 140: $195-202$.

Mustonen A.M., S a a re la S., Pyy k on en T., Ni e m in en P. (2005 b). Endocrinologic adaptations to wintertime fasting in the male American mink (Mustela vison). Exp. Biol. Med., 230: $612-620$.

P a p u c C., G or a n G.C., Pre de s c u C.N., N i c or e s c u V. (2017). Mechanisms of oxidative processes in meat and toxicity induced by postprandial degradation products: a review. Comp. Rev. Food Sci. Food Saf., 16: 96-123.

Pedersen V., J e p pes e n L.L., J e p pes en N. (2004). Effects of group housing systems on behaviour and production performance in farmed juvenile mink (Mustela vison). App. J. Anim. Behav. Sci., 88: 89-100. 
P i ó r k ow s k a M., K ow a l s k a D. (2014). Characteristics of farmed and wild populations of American mink (in Polish). Wiad. Zoot., 2: 122-129.

Pölön en I., K o e n e m H., Søn d e rup M. (2004). A systematic approach to sustainable fur farming with special reference to feed and feeding. Scientifur, 28: 96-99.

R o u vinen - Wa t t K., Hy nes A.M. (2004). Mink nursing sickness survey in North America. Scientifur, 28: 71-77.

R o ze m p ols ka - R u c ińs ka I. (2004). Genetic background of performance and functional traits in mink. EJPAU, www.ejpau.media.pl/series/volume7/issue2/animal/art-03.html

S c h a c k e 1 f o r d R.M. (1952). Superfetation in the ranch mink. Am. Natur., 86: 311-319.

$\mathrm{S}$ c h n e i d e r R.R., H u n ter D.B. (1992). Nursing disease in mink. Scientifur, 16: 239-242.

S chneid e r R.R., Hunter D.B., Wa 1 t ne r - To e w s D. (1992). Nursing disease in mink: ranchlevel epidemiology. Prev. Vet. Med., 14: 181-194.

S chneider R.R., Hunter D.B. (1993). A survey of the causes of mortality in adult mink, with emphasis on the lactation period. Can. Vet. J., 34: 103-108.

Seremak B., Dziadosz M., Felska-Błaszczyk L., Lasota B., Pławski K., Masłowska A. (2011). A novel arrangement of breeding sets has a positive effects on some reproductive parameters in females of the American mink (Neovison vison). Acta Sci. Pol. Zootech., 10: $105-114$.

Seremak B., Dziadosz M., Lasota B., Felska-Błaszczyk L., Pławski K., Masłowska A., Mieleńczuk G. (2011). Effect of the quality of handling and care on the reproduction parameters of mink. Acta Sci. Pol., Zootech., 10: 93-102.

Seremak B., Felska-Błaszczyk L., D worecka M., Dzi a dos z-S tyś M., Las ot a B. (2013). Analysis of litter sizes at birth and at 7 days of nursing in mink (Neovison vison) of Black Velvet, Hedlund White, and Silverblue color types. Acta Sci. Pol., Zootech., 12: 39-48.

Seremak B., Felska-Błaszczyk L., Pławski K., Opieka P., Wojciechowska A. (2016). Selected reproductive parameters of female American mink (Neovison vison) of different colour variants (in Polish). Wiad. Zoot., 2: 43-48.

S o cha S., K ołodzi ej c z y k D. (2006). Analysis of factors affecting fertility in standard and palomino mink (in Polish). Ann. UMCS, Sectio EE, 24: 403-408.

S o cha S., Marki ew i c z D., Wojew ó dzka A. (2003). Selected reproductive parameters of female American mink (Neovison vison) of different colour variants (in Polish). Zesz. Nauk. Prz. Hod., 68, 6: 79-86.

S o cha S., Marki ew i c z D. (2002). Effect of mating and whelping dates on the number of pups in mink. EJPAU, Anim. Husb., 5: http://www.ejpau.media.pl

Sulik M., F elska-B laszczyk L., Z ołedzieje w ska J., S e mik A. (2008). Analysis of reproduction performance under different mating systems in Sapphire and Wild mink. Scientifur, 32: $100-105$.

Sund qvist C., A m a d or A.G., B artke A. (1989). Reproduction fertility (Mustela vison). J. Reprod. Fertil., 85: 413-441.

S vends en P.M., H a n s en B.K., Malmkvist J., Han s en S.W., P a 1 m e R., J e p p e s en L.L. (2007). Selection against stereotypic behaviour may have contradictory consequences for the welfare of farm mink (Mustela vison). App. Anim. Behav. Sci., 107: 110-119.

Ślaska B., Rozempolska-Rucińska I., Jeżewska-Witkowska G. (2009). Variation in some reproductive traits of mink (Neovison vison) according to their coat colour. Ann. Anim. Sci., 9: 287-297.

Św ięc i c ka N., B e rn a ck a H., Z a w iśla k J. (2016). Reproductive results of mink of different colour types on farms under performance recording and breeding value estimation in the years 1999-2013 (in Polish). Wiad. Zoot., 1: 61-67.

Ś w i ę c i c k a N. (2013). Influence of the air temperature and relative air humidity on the parameters of the reproduction of Scanbrown minks. JCEA, 14: 407-419.

Tar a s k a M., S u l i k M., L a s o t a B. (2016). Comparison of the craniometric parameters of wild and farm American mink (Mustela vison). Folia Morphol., 75: 251-256.

Ta u s o n A.H. (1988). Flushing of mink. Effects of level of preceding feed restriction and length of flushing period on reproductive performance. Anim. Reprod. Sci., 17: 243-250.

T a u s o n A.H. (1993). Effect of body condition and dietary energy supply on reproductive processes in female mink (Mustela vison). J. Reprod. Fertil., 47(Suppl.): 37-45. 
Taus on A.H., Fink R., F ors berg M., La gerkvis t G., Wa mberg S. (2000). LH release in mink (Mustela vison). Pattern of the LH surge and effect of metabolic status. Reprod. Nutr. Dev., 40: 229-247.

Thirstrup J.P., Ruiz-Gonzalez A., Pujolar J.M., Larsen P.F., Jensen J., Randi E., Zalewski A., Pertoldi C. (2015). Population genetic structure in farm and feral American mink (Neovison vison) inferred from RAD sequencing-generated single nucleotide polymorphisms. J. Anim. Sci., 93: 1-10.

Tr a p e z o v O.V. (2008). Effects of domestication and new technological possibilities in breeding practice: American mink (Neovison vison Schreber, 1777) as a model. Scientifur, 32: 63-68.

W i e r z b i c k i H. (2005). Breeding value evaluation in Polish fur animals: Factors affecting pelt prices in the international trading system. CJAS, 50: 266-272.

Received: 3 X 2018

Accepted: 12 XII 2018 